\title{
Solitary necrotic nodule of the liver: parasitic origin?
}

\author{
WMS Tsui, RWS Yuen, LTC Chow, CCH Tse
}

\begin{abstract}
Aims: To report further cases of solitary necrotic nodule of the liver and to study its nature.

Methods: Seven nodules were retrieved from 4000 necropsy and surgical liver specimens coming to light over the past five years. All of them satisfied the diagnostic criteria of solitary necrotic nodule: a solid lesion with a central necrotic core and a hyalinised fibrotic capsule containing elastic fibres. Their clinicopathological features were reviewed.

Results: The nodules were incidental findings at surgery or necropsy in four men and three women whose ages ranged from 48 to 79 years (mean 63.7 years). Four were found in the right lobe and three in the left. Six were subcapsular and only one deep in the parenchyma, with sizes ranging from $0.3-2.5 \mathrm{~cm}$. Each of them was solitary, well demarcated, and round to oval with a firm, whitish rim and a core of yellowish white cheese-like to solid material. In addition to the basic architecture, there were a number of common and undescribed histological features: presence of varying numbers of small mural vessels with intimal fibrosis and obliteration, presence of cholesterol clefts and foamy cells among necrotic material, and sparsity of inflammatory cells. In the two cases where ghosts of degenerated cells and partially preserved liver reticulin pattern were noted, worms were identified, one being Clonorchis sinensis.

Conclusions: The entity is believed to be a "burnt-out phase" of a variety of benign lesions. Parasitic infestation is another possible cause, and presence of ghosts of degenerate cells, partially preserved liver reticulin pattern, cholesterol clefts and foamy cells among necrotic material are auxiliary features pointing to such an aetiology. The variation in morphological
\end{abstract}

fine details reflects both the lesion's diverse pathogenesis and the fact that it can be of varying duration.

$(f$ Clin Pathol 1992;45:975-978)

In 1983 Shepherd and Lee described five cases of solitary necrotic nodule of the liver, comprising a central necrotic core and enclosed by a hyalinised fibrotic capsule containing elastic fibres; they emphasised that these lesions might be mistaken surgically for metastases. ${ }^{1}$ The lesion was believed to be an entity of diverse pathogenesis. Subsequently Berry reported two more cases and suggested that they were probably all sclerosed haemangiomas. $^{23}$ The original author objected to this view and proposed that effete larval granulomas were an important cause among other possible mechanisms. ${ }^{4}$ Recently an origin in haemangioma has been reaffirmed.

\section{Methods}

Seven cases were retrieved from 1000 surgical liver specimens and 3000 necropsies coming to light over the past five years. All of them satisfied the diagnostic criteria of solitary necrotic nodule: a solid lesion with a central necrotic centre and a hyalinised fibrotic capsule. All of them were incidental findings at necropsy or surgery. The clinical and pathological findings are summarised in table 1 .

The three postmortem and four wedge biopsy specimens had been routinely fixed in neutral buffered formalin and processed in the usual way for paraffin wax embedding and step sectioning at $4 \mu \mathrm{m}$. The sections were stained with haematoxylin and eosin, periodic acid Schiff (PAS) diastase, Perls's, reticulin, orcein, elastic van Gieson and chromotrope aniline blue. Ziehl-Neelsen and Gram stains were performed to exclude bacterial infection.

Table 1 Clinical and pathological features of solitary necrotic nodules

\begin{tabular}{|c|c|c|c|}
\hline Case No & Sex/age & Site and size of nodule & Other surgical/postmortem findings \\
\hline 1 & $\mathbf{M} / 70$ & $\begin{array}{l}\text { Subcapsular anterior surface of left } \\
\text { lobe, } 1 \mathrm{~cm}\end{array}$ & $\begin{array}{l}\text { Necropsy: acute myocardial infarction, concentric left ventricular hypertrophy, generalised athero- } \\
\text { sclerosis, acute cerebral infarction, benign nephrosclerosis, bilateral pulmonary oedema and old } \\
\text { tuberculosis fibrocaseous nodule in right lung apex }\end{array}$ \\
\hline 2 & M/65 & Deep in right lobe, $2.5 \mathrm{~cm}$ & $\begin{array}{l}\text { Necropsy: perforation of ileum with generalised peritonitis, aspiration pneumonia and bilateral } \\
\text { renal stones. }\end{array}$ \\
\hline 3 & $\mathrm{~F} / 61$ & $\begin{array}{l}\text { Subcapsular anterior surface of right } \\
\text { lobe, } 1 \mathrm{~cm}\end{array}$ & $\begin{array}{l}\text { Necropsy: acute subdural haematoma, concentric let ventricular hypertrophy, left pleural effusion } \\
\text { and advanced glomerulosclerosis }\end{array}$ \\
\hline 4 & M/79 & $\begin{array}{l}\text { Subcapsular anterior border of right } \\
\text { lobe, } 1.5 \mathrm{~cm}\end{array}$ & Surgery: a stone found impacted at lower end of common bile duct with acute cholangitis \\
\hline 5 & $\mathrm{~F} / 48$ & $\begin{array}{l}\text { Subcapsular anterior surface of left } \\
\text { lobe, } 5 \mathrm{~mm}\end{array}$ & $\begin{array}{l}\text { Surgery: multiple stones in dilated gallbladder, common bile duct and left intrahepatic bile ducts } \\
\text { Subsequent stool examination did not reveal any parasitic ova }\end{array}$ \\
\hline 6 & F/61 & $\begin{array}{l}\text { Subcapsular anterior surface of left } \\
\text { lobe, } 3 \mathrm{~mm}\end{array}$ & Surgery: Dukes' stage C adenocarcinoma of rectum. \\
\hline 7 & M/62 & $\begin{array}{l}\text { Subcapsular anterior border of right } \\
\text { lobe, } 4 \mathrm{~mm}\end{array}$ & $\begin{array}{l}\text { Previous carcinoma of larynx with laryngectomy. Operation: carcinoma of oesophagus with } \\
\text { lymph node metastasis. }\end{array}$ \\
\hline
\end{tabular}




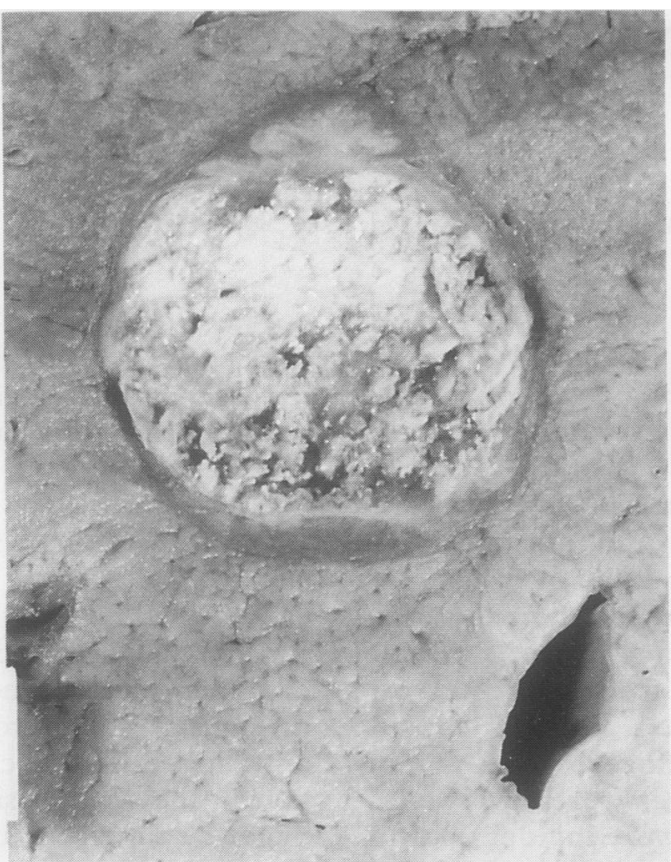

Figure 1 Solitary necrotic nodule with well defined capsule deep in the liver parenchyma in case 2 (white vertical bar at left lower corner indicates $1 \mathrm{~cm}$ ).

\section{Results}

Each of the nodules was solitary, well demarcated, and round to oval with a firm whitish rim and a core of yellowish white cheese-like to solid material (fig 1) (table 1). The nodule in case 3 had serpiginous deep parenchymal extension.

MICROSCOPIC FINDINGS

All seven specimens shared similar histological features. The inner aspect of the wall consisted of dense hyalinised fibrous tissue. The outer portion also had varying amounts of elastic fibres and varying numbers of small arteries and veins with intimal thickening, duplication of elastic fibres, and partial obliteration of lumina (fig 2). A sprinkling of mononuclear inflammatory cells were present in the wall, concentrated near the interface with the surrounding parenchyma. There was no granulomatous inflammation or eosinophilic infiltrate. Bile duct proliferation was not a feature in the

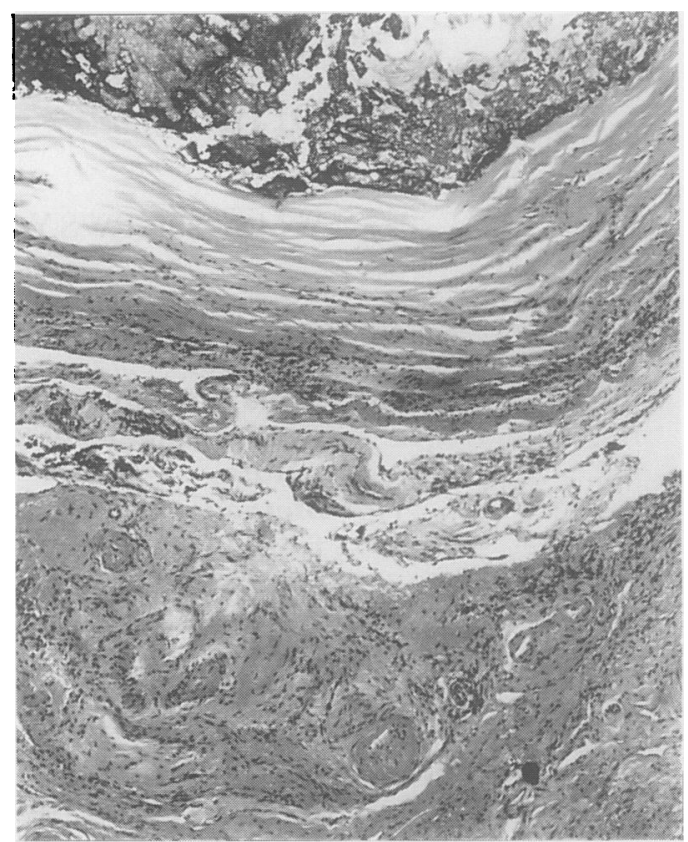

Figure 2 Wall of the nodule from case 4. Note masses of elastic fibres and many partially obliterated vessels in the outer aspect (haematoxylin and eosin).

periphery. The centre comprised mainly necrotic, eosinophilic granular material in variable combination with basophilic globular calcification, cholesterol clefts, and foamy cells. Ossification was seen in cases 6 and 7. There were no haemosiderin deposits. Ziehl-Neelsen, Gram, and PAS stains failed to reveal any bacteria or fungi. The pertinent features are detailed in table 2 .

In case 3 there was a large conducting portal tract pointing towards the deep serpiginous portion of the nodule. An adult Clonorchis sinensis lay within a medium-sized bile duct the epithelial lining of which showed hyperplastic changes (fig 3 ). In case 5 the outline of a degenerated larva could be seen in the necrotic centre; the larva measured $65 \mu \mathrm{m}$ in maximum width and appeared to be invested by a cuticle (fig 4). In both cases ghosts of degenerate cells and a partially preserved liver reticulin pattern were noted in the necrotic centre.

Table 2 Histological features

\begin{tabular}{|c|c|c|c|c|c|c|c|}
\hline \multirow[b]{2}{*}{ Features } & \multicolumn{7}{|l|}{ Case No } \\
\hline & $\overline{1}$ & 2 & 3 & $4^{*}$ & $5^{*}$ & $6^{*}$ & $7^{\star}$ \\
\hline $\begin{array}{l}\text { Capsule wall: } \\
\text { Fibrosis (inner) } \\
\text { Elastic (outer) } \\
\text { Vessels (outer) } \\
\text { Mononuclear cells }\end{array}$ & $\begin{array}{l}+++ \\
+++ \\
+++ \\
+\end{array}$ & $\begin{array}{l}++ \\
+ \\
+ \\
+\end{array}$ & $\begin{array}{l}++ \\
+ \\
+ \\
+\end{array}$ & $\begin{array}{l}++ \\
+++ \\
+++ \\
+\end{array}$ & $\begin{array}{l}++ \\
+ \\
++ \\
+\end{array}$ & $\begin{array}{l}++ \\
+ \\
+ \\
+\end{array}$ & $\begin{array}{l}++ \\
++ \\
+ \\
+\end{array}$ \\
\hline $\begin{array}{l}\text { Centre: } \\
\text { Amorphous material } \\
\text { Calcification } \\
\text { Cholesterol clefts } \\
\text { Foam cells } \\
\text { Preserved liver reticulin } \\
\text { Shadows of degenerated cells } \\
\text { Adjacent liver }\end{array}$ & $\begin{array}{l}+++ \\
+ \\
++ \\
++ \\
0 \\
0 \\
\text { Shock }\end{array}$ & $\begin{array}{l}+++ \\
++ \\
+ \\
+ \\
0 \\
0 \\
\text { Steatosis }\end{array}$ & $\begin{array}{l}++ \\
0 \\
0 \\
0 \\
+ \\
++ \\
\text { Conges- } \\
\text { tion }\end{array}$ & $\begin{array}{l}++ \\
++ \\
++ \\
++ \\
0 \\
0 \\
\text { N/A }\end{array}$ & $\begin{array}{l}++ \\
+ \\
0 \\
0 \\
+ \\
+ \\
+ \\
\text { N/A }\end{array}$ & $\begin{array}{l}+ \\
+++ \\
0 \\
0 \\
0 \\
0 \\
\text { Steatosis }\end{array}$ & $\begin{array}{l}++ \\
+ \\
+ \\
0 \\
0 \\
+ \\
\text { Normal }\end{array}$ \\
\hline
\end{tabular}

Histological changes were evaluated semiquantitatively on a scale ranging from absent $(0)$ to mild $(+)$, moderate $(++)$ and massive $(+++)$.

^Antemortem specimen; N/A: No liver tissue available for assessment. 


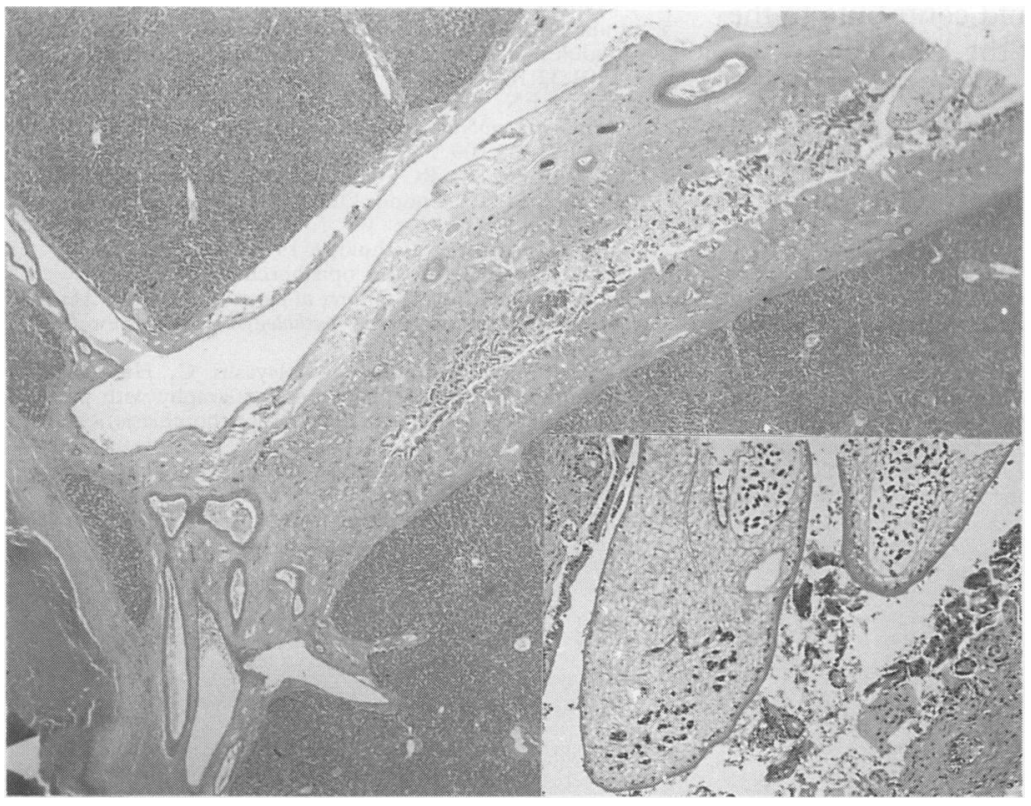

Figure 3 Liver lesion in case 3. A large conducting portal tract containing Clonorchis sinensis at the right upper corner was pointing towards the nodule at the left lower corner. Inset: the fluke at a higher magnification (haematoxylin and eosin).

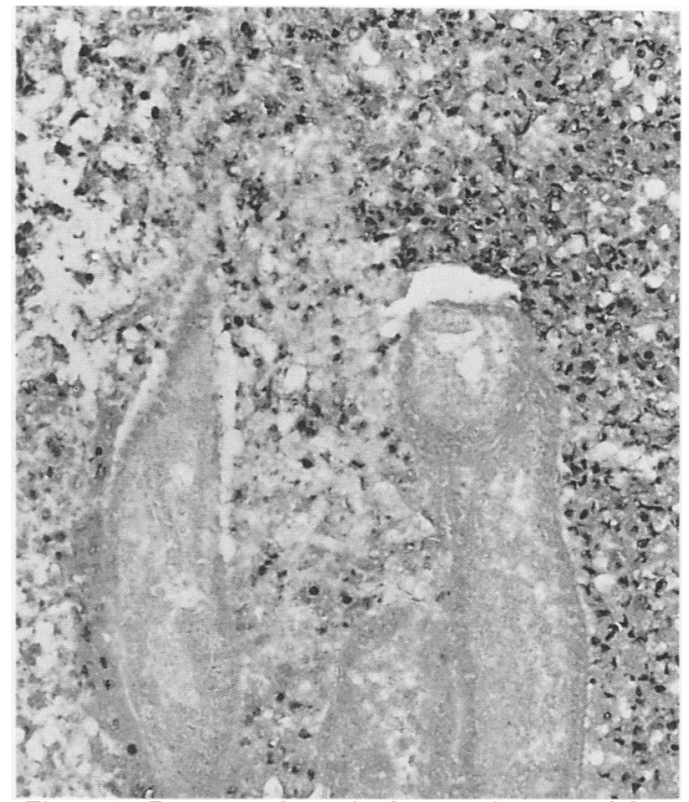

Figure 4 Degenerate larva in the necrotic centre of the nodule from case 5 . Note many degenerate cells in the surrounding tissue (haematoxylin and eosin).

\section{Discussion}

This study, comprising seven cases, represents the largest series of solitary necrotic nodules of liver so far reported. The cases showed several common and undescribed features which shed light on the pathogenesis of this lesion. The cholesterol and foamy cells occur as the cellular centre becomes degraded. The persistence of the central necrotic material is probably due to formation of a dense fibrotic wall with obliterated vessels which prevents its resorption. As the basic histological features of the solitary necrotic nodule are not specific, consisting merely of a fibrous capsule and a central core of nondescript necrotic material, it is highly probable that this is not a lesion having a specific aetiology but a "burnt-out phase" of a variety of benign lesions. However, among those nodular lesions that resolve spontaneously but incompletely leaving a necrotic centre, infective abscesses, parasitic granulomas, and haematoma are more likely to evolve in this way than benign tumours. It has also been noted that the capsule of intrahepatic granulomas containing nematodes has a very similar histological appearance to that of the solitary necrotic nodule. ${ }^{6}$ In this report we have documented that parasitic infestation is a cause in two of the cases. Clonorchis sinensis was present in an adjacent bile duct in case 3 and the topographical association suggests that the fluke is the causative agent rather than a simple coincidence. The trematode has not been associated with such a lesion before, but solitary cysts similar to abscess or hydatid cyst have been described in patients with opisthorchiasis in a cholangiography study. ${ }^{7-9}$ The larva in case 5 was actually present within the nodule and was too degenerate to permit identification of its exact species. We postulate that the parasite is arrested beneath the liver capsule during its migration through the liver as part of its normal or ectopic life cycle and becomes encapsulated to form a fibrosing nodule. This accounts for the predominantly subcapsular position of the reported nodules.

We were unable to demonstrate a haemangiomatous structure or reticulin pattern in the collars or within the necrotic centre, as described in a recent study. ${ }^{5}$ On the other hand, calcification, cholesterol clefts, foamy cells and degenerate cells, which were notable features in our series, were absent in that study. This discrepancy in fine details is best explained by a difference in aetiology; a parasitic process seems to be prevalent in our locality.

The lesion tends to affect the elderly but often a cause is found in younger patients. The histological characteristics of the two parasitic cases-namely, less abundant elastics, degenerate ghost cells, and preserved liver reticulin pattern-also suggest these two are relatively early lesions. Most of the nodules are therefore probably longstanding so that the original aetiology has become obscure. The variation in the histological features of solitary necrotic nodules reflects not only the diverse aetiology but also the different age of the lesion.

This is an uncommon lesion and only seven cases have been identified in a five year period among 4000 necropsy and surgical liver specimens, giving an incidence similar to that of Berry's series. ${ }^{10}$ The nodules were asymptomatic and discovered only incidentally. They were small; the largest one was $2.5 \mathrm{~cm}$ in diameter (case 2). Twenty of the 21 reported nodules (including the present seven cases) were either subcapsular or close to the anterior margin and hence readily detectable on casual superficial examination at operation. Deep seated ones such as that in case 2 would have been missed unless some imaging investigations or careful postmortem examinations were performed. Many similar lesions of known causation would probably not be identified as 
such. All these factors would contribute to the apparent low incidence of the lesion.

Finally, we concur with the original authors' view that these nodules are not malignant in origin and that the term "fibrosing necrotic nodule" might be more appropriate because they may be multiple. ${ }^{45}$

1 Shepherd NA, Lee G. Solitary necrotic nodules of the liver simulating hepatic metastases. f Clin Pathol 1983;36:1181-3.

2 Berry CL. Solitary necrotic nodule of liver; a non-existent lesion. F Pathol 1985;146:263A.

3 Berry CL. Solitary "necrotic nodule" of the liver: a probable pathogenesis. $\mathcal{f}$ Clin Pathol 1985;38:1278-80.

4 Shepherd NA. Solitary necrotic nodule. F Clin Patho
1990;43:348-9.

5 Sundaresan M, Lyons B, Akosa AB. "Solitary" necrotic nodules of the liver: an aetiology reaffirmed. Gut nodules of the
$1991 ; 32: 1378-80$

6 Mondou EN, Gnepp DR. Hepatic granuloma resulting from Enterobius vermicularis. Am $\mathcal{f}$ Clin Pathol 1989;91:97-100

7 Dooley JR, Neafie RC. Clonorchiasis and opisthorchiasis. In: Binford CH, Connor DH, eds. Pathology of tropical and extraordinary diseases. Vol 1. Washington DC: Armed Forces Institute of Pathology, 1976:509-16.

8 Sun T. Clonorchiasis and opisthorchiasis. In: Sun T, ed. Pathology and clinical features of parasitic diseases. (Masson monographs in diagnostic pathology. Vol 5) New York: Masson, 1982:243-52.

9 Viranuvatti V, Pengvanit U, Kalayasiri C, Hitanant S. Percutaneous transhepatic cholangiography with particular reference to liver flukes (opisthorchiasis). $A m \quad \mathcal{F}$ ular reference to liver
Proctol 1966;17:450-61.

10 Berry CL. Liver lesions in an autopsy population. Hum Toxicol 1987;6:209-14. 